This article may not exactly replicate the final version published in the APA journal. It is not the copy of record. 


\title{
When Accuracy Hurts: Reactions of Anxiously-Attached Dating Partners to a Relationship-Threatening Situation
}

\author{
Jeffry A. Simpson William Ickes \\ Texas A\&M University University of Texas at Arlington \\ Jami Grich Stevens \\ Texas A\&M University
}

Running Head: Attachment

Author Notes: Correspondence with the authors should be addressed to Jeffry A. Simpson, Department of Psychology, Texas A\&M University, College Station, TX, 77843-42325 or William Ickes, Department of Psychology, University of Texas, Arlington, TX, 76019-0528. We thank Rebecca Bruecker, Roberto Garcia, Luis Gonzalez, Shanae D. Jennings, Eric Schreiber, James Webb, and Ryan Whitfall for their assistance with this research project, and we thank John Finch and Richard Gonzalez for their statistical advice.

February 16, 1997 


\begin{abstract}
Why are individuals who are anxious and uncertain about their partner's love and commitment especially likely to have turbulent and unstable relationships? Guided by three theoretical perspectives_-Ickes and Simpson's (1997) model of empathic accuracy in relationships, Bowlby's $(1969,1973)$ attachment theory, and Holmes and Rempel's (1989) appraisal model of trust, we examined how one psychological process-heightened empathic accuracy in relationship-threatening situations - might be associated with personal and relational distress. The participants inferred their dating partner's thoughts and feelings from a videotaped interaction in which they and their partner rated and discussed slides of either highly attractive or less attractive opposite-sex individuals. The data revealed that the more anxious individuals were more accurate when they inferred their partner's thoughts and feelings in this relationshipthreatening situation; however, their own reported thoughts and feelings indicated greater distress and less confidence in themselves and their partner/relationship. Following the evaluation task, the more anxious individuals reported a slight yet statistically significant decrease in the perceived closeness of their relationship. Four months later, the relationships of the more anxious individuals were more likely to have ended. These findings, along with some additional results for avoidantly attached individuals, are discussed in terms of the three theoretical perspectives from which our predictions were derived.
\end{abstract}




\section{When Accuracy Hurts: Reactions of Anxiously-Attached}

\section{Dating Partners to a Relationship-Threatening Situation}

Why are people who are anxious and uncertain about their partner's love and commitment especially likely to have turbulent and unstable relationships? Recent studies have shown that "anxious-uncertain" individuals are more likely than their less-anxious counterparts to have relationships characterized by intense conflict (Pistole, 1989; Simpson, Rholes, \& Phillips, 1996), pronounced emotional ups-and-downs (Tidwell, Reis, \& Shaver, 1996), and greater vulnerability to dissolution (Hazan \& Shaver, 1987; Kirkpatrick \& Hazan, 1994; Shaver \& Brennan, 1992). These and conceptually similar findings have been documented by researchers working from different theoretical perspectives, including adult attachment theory (see Hazan \& Shaver, 1994, and Shaver, Collins, \& Clark, 1996, for reviews), the appraisal model of relational trust (Holmes, 1991; Holmes \& Rempel, 1989), and dispositional theories of emotional instability (Bentler \& Newcomb, 1978; Bolger \& Schilling, 1991; Kelly \& Conley, 1987).

Relatively little is known about the specific social-psychological processes that produce and sustain these negative outcomes. There is a growing consensus, however, that these outcomes may derive from the way that highly anxious-uncertain people perceive and respond to relationship-threatening situations (cf. Ickes \& Simpson, 1997). The purpose of the present study was to explore how one specific psychological process - greater empathic accuracy about the thoughts and feelings harbored by one's romantic partner in a relationship-threatening situation - might be associated with both personal and relational distress. As an important exception to the general rule that "To understand all is to forgive all," we propose that, by understanding the private thoughts and feelings of their partners too well in relationshipthreatening situations, more anxious-ambivalent individuals illustrate the contrasting case in which "To understand all is to forgive nothing."

\section{Ickes and Simpson's (1997) Empathic Accuracy Perspective}

The notion that greater empathic accuracy can, in some circumstances, actually harm relationships led Ickes and Simpson (1997) to propose a model of how empathic accuracy is "managed" in relationship-threatening versus non-threatening situations. The model contends

that, contrary to conventional wisdom, greater understanding of a relationship partner's thoughts 
and feelings is not always a good thing. Although greater empathic accuracy tends to be positively correlated with enhanced relationship satisfaction and stability in situations that pose little or no threat to relationships (e.g., Kahn, 1970; Noller, 1980; Noller \& Ruzzene, 1991), empathic accuracy tends to be negatively correlated with satisfaction and stability in relationshipthreatening situations (e.g., Sillars, Pike, Jones, \& Murphy, 1984; Simpson, Ickes, \& Blackstone, 1995; for a review, see Ickes \& Simpson, 1997, pp. 223-224).

Ickes and Simpson (1997) propose that there are "danger zones" in any close relationship — areas in which painful insights or revelations about a partner's private thoughts and feelings might occur (e.g., positive feelings about old flames or provocative thoughts about attractive people). Accordingly, partners in close relationships often learn to identify and steer away from such danger-zone topics in order to avoid damaging their own self-esteem, their esteem for their partner, or the relationship itself. Occasionally, however, partners find themselves in situations in which their first line of defense - avoiding or evading danger-zone issues - is not an option.

In these relationship-threatening situations, the empathic accuracy model predicts that each partner's second line of defense is motivated inaccuracy - a conscious or unconscious failure to accurately infer the specific content of their partner's potentially harmful thoughts and feelings. When partners display motivated inaccuracy (effectively "turning a blind eye" to what the other is thinking and feeling), relational satisfaction and stability should be — and apparently aremaintained even in highly threatening situations (see Simpson et al., 1995). On the other hand, if partners accurately infer each other's thoughts and feelings in these relationship-threatening situations, they may wind up "wiser but sadder," learning just how threatening their partner's thoughts and feelings really are but paying a high price in terms of greater distress, relational instability, and dissatisfaction. ${ }^{1}$

How should highly anxious-uncertain individuals react in relationship-threatening situations? Should they display little empathic accuracy and experience little personal and relational distress, or should they display increased empathic accuracy followed by greater personal and relational distress? Ickes and Simpson's (1997) empathic accuracy model does not specifically address these questions. However, converging predictions can be derived from both 
attachment theory (Bowlby, 1969, 1973; Cassidy \& Berlin, 1994) and from Holmes and Rempel's (1989) appraisal model of trust in relationships (see also Holmes, 1991).

\section{The Attachment Theory Perspective}

Because they have received inconsistent or unpredictable care and support from past attachment figures (see Cassidy \& Berlin, 1994, for a review), highly anxious (or preoccupied) individuals "have no confidence that [attachment figures] will ever be truly available and dependable. Through their eyes the world is seen as comfortless and unpredictable" (Bowlby, 1973, pp. 208). Consequently, such persons develop negative working models about themselves as relationship partners, viewing themselves as unworthy of love and affection. On the other hand, because they have not experienced consistently strong rejection from attachment figures, highly anxious people harbor positive (hopeful) yet guarded and apprehensive working models about whether significant others are likely to be available and emotionally-supportive relationship partners (Bartholomew \& Horowitz, 1991; Hazan \& Shaver, 1987). Although many factors can activate the attachment system in highly anxious persons, the strongest activators are situations "that shake a person's confidence that his attachment figures will be available to him when desired" (Bowlby, 1973, pp. 213).

According to Bowlby $(1969,1973)$ and Cassidy and Berlin (1994, pp. 972), highly anxious individuals should do three things in response to chronic uncertainty about the availability of their attachment figures. First, they should display heightened, easily activated attachment behavior (e.g., showing signs of greater distress), particularly in situations that raise the possibility of losing their attachment figure. Second, they should closely "monitor" their attachment figure in these situations, especially if the knowledge gained could be used to keep the attachment figure closer and more psychologically available in the future. Third, due to their heightened distress and closer monitoring, anxious individuals should find it more difficult to engage in and pursue other major life tasks.

Empirical research supports these claims. Highly anxious adults display greater relationship-centered distress and anxiety (Brennan \& Shaver, 1995; Feeney, 1998; Hazan \& Shaver, 1987; Kobak \& Sceery, 1988), especially in situations that portend eventual relationship loss or abandonment (the prospect of death: Mikulincer, Florian, \& Tolmacz, 1990; the fear of 
harm due to possible missile attacks: Mikulincer, Florian, \& Weller, 1993; trying to resolve a major relationship-based problem with their dating partner: Simpson et al., 1996). In addition, highly anxious adults typically "direct attention toward distress and attachment figures in a hypervigilant manner" (Kobak \& Sceery, 1988, pp. 142), and are described as being "hypervigilant to sources of distress" (Mikulincer et al., 1993, pp. 824). According to attachment theory and research, therefore, more anxious individuals should display higher levels of empathic accuracy (i.e., greater attention and sensitivity to their partner's thoughts and feelings) as well as higher levels personal and relational distress, particularly in situations that threaten the stability and permanence of their relationships (see also Main, 1990).

As a prototypic example of a relationship-threatening situation, consider a scenario in which dating partners evaluate the attractiveness of opposite-sex persons in each other's presence. This type of situation is likely to be encountered, at least occasionally, during the early stages of relationship development. When faced with this potentially relationship-threatening situation, highly anxious individuals should (a) display heightened empathic accuracy (i.e., they should infer the content of their dating partner's thoughts and feelings more accurately than less-anxious individuals), (b) feel more threatened, and (c) report more distressed thoughts and feelings. Because their partners are likely to be having thoughts or feelings that could threaten the relationship (e.g., thoughts or feelings about the physical attractiveness or sexual appeal of other people as potential dating partners), more anxious individuals should also (d) report at least temporary declines in the perceived closeness of their relationships following relationshipthreatening interactions (see Simpson et al., 1996, for indirect support for this prediction).

Finally, if highly anxious individuals do in fact respond to relationship-threatening situations by more accurately "reading" their partner's potentially threatening thoughts and feelings, their relationships should be more susceptible to dissolution. This prediction does not imply that relationship dissolution should be precipitated by a single, relationship-threatening interaction. Rather, relationship dissolution is assumed to be a cumulative, dispositionallydriven outcome of the many relationship-threatening situations that highly anxious individuals are likely to encounter and then respond to in the emotionally reactive and destabilizing manner we have described. 


\section{The Appraisal Model of Trust: Parallels with Attachment Theory}

Trust is one component of attachment security (Bowlby, 1982, pp. 340). Research has shown that the degree to which individuals trust their relationship partners is systematically related to different adult attachment styles. In general, securely attached individuals are more likely to trust their partners than are anxiously attached individuals, who in turn are more trusting than are avoidantly attached individuals (Brennan \& Shaver, 1995; Hazan \& Shaver, 1987). In other words, securely attached people tend to be "high trusting" individuals, anxious people tend to be more "uncertain" in their level of trust, and avoidant people tend to be "low trusting." Given these parallel associations, it is worth noting that Holmes and Rempel's (1989) appraisal model of relational trust (see also Holmes, 1991) makes predictions that are generally consistent with those of attachment theory. Jones, Couch, and Scott (1997) have summarized the appraisal model's general predictions as follows:

High trusting individuals do not judge single events as having much weight in determining the outcome or quality of a relationship. Positive events are viewed as confirming the trust that has been given, and single negative events are not seen as a threat to the relationship...Individuals uncertain about trusting... are motivated to reduce uncertainty. These individuals actively assess their partner's motives....Positive behaviors are readily viewed as relevant to greater matters of loving or caring. Negative behaviors are also perceived as very important, relating to the overall appraisal of the relationship. Risk is greatest at this level of trust because a single negative event has heightened implications for the continuation of the relationship....Low-trust partners are likely to approach their relationship with a relatively closed mind, which is very similar to the strategy of high-trust [partners].... They are suspicious of positive behaviors and proceed cautiously. On the other hand, negative behaviors are likely to reinforce the lack of trust that previously exists (p. 474, brackets and italics ours).

According to the trust appraisal model, individuals who are "uncertain" about trusting others (i.e., those with an anxious attachment orientation) should react to relationship-threatening situations by (a) actively trying to assess their partner's motives, and (b) drawing strong conclusions about the overall status of their relationship from single negative events. If highly anxious-uncertain individuals focus on the negative implications of relationship-threatening situations, the consequences of accurately inferring their partner's thoughts and feelings should 
be more deleterious to their relationships than to those of less anxious-uncertain individuals. Hence, attachment theory and the appraisal model of trust converge in predicting that more anxious-uncertain individuals should be more attentive and emotionally reactive to their partner's behavior in relationship-threatening situations. We contend that these responses should occur regardless of whether the partner's "behavior" takes the form of overt actions or covert thoughts and feelings (Ickes and Simpson, 1997).

\section{Predictions}

In summary, our major predictions - derived from both attachment theory and the appraisal model of trust - center on how anxious-uncertain individuals ought to think, feel, and behave in a relationship-threatening context. Specifically, more anxious individuals should:

(H1): display greater empathic accuracy than less anxious individuals in a relationship-threatening situation,

$(\mathrm{H} 2)$ feel more threatened and report more distressed thoughts and feelings in such a situation,

(H3): $\quad$ report at least a temporary decline in the perceived closeness of their relationship following the relationship-threatening interaction, and

(H4): $\quad$ have relationships that are more likely to terminate within 4 months.

Ickes and Simpson's (1997) model posits that low empathic accuracy can serve as a buffer against negative relationship outcomes when relationships are threatened. If highly anxious-uncertain individuals tend to accentuate the negative implications of single, isolated relationship-threatening events whereas less anxious-uncertain individuals tend to overlook or downplay these events (Holmes \& Rempel, 1989), the consequences of accurately inferring their partner's thoughts and feelings should be more negative for highly anxious individuals. This reasoning suggests the following prediction:

(H5): Individuals who are highly anxious about their relationship and who display heightened empathic accuracy in a relationship-threatening situation should be particularly susceptible to decreases in subjective closeness (in the short- 
term) and to relationship dissolution (in the long-term). In other words, the association between empathic accuracy and either changes in closeness or relationship dissolution should be moderated by individuals' level of attachment anxiety in relationship-threatening situations.

\section{Overview of the Present Study}

The present study is based on extensive new analyses of self-report and observer-rated measures that either were not available or were not analyzed in a study previously reported by Simpson et al. (1995). In the Simpson et al. study, 82 heterosexual dating couples rated the physical and sexual attractiveness of alternative dating partners who were ostensibly participants in a local "dating pool." Each couple was randomly assigned to view and rate a set of either highly attractive or less attractive alternative partners. The rating task was designed to create a relationship-threatening situation for all of the couples in the study, but the degree of threat was expected to be somewhat greater for couples who rated highly attractive alternative partners than for those who rated less attractive ones. Each of a set of six slides depicting an opposite-sex target person was rated aloud (on 10-point scales measuring physical attractiveness and sexual appeal) by the appropriate (male or female) dating partner. Following the verbal ratings for each slide, both partners discussed what they liked or disliked about each target person. Each couple's interaction during this rating-and-discussion task was unobtrusively videotaped.

Both partners then viewed a copy of the videotape in separate rooms, indicating the times during the interaction when they had a specific thought or feeling and writing down its content in sentence form. Following this thought/feeling assessment, each partner was then asked to infer (as accurately as possible) what the other was thinking or feeling at each point during the interaction when the other reported having a specific thought or feeling. The partners' levels of empathic accuracy were then calculated using procedures developed by Ickes, Stinson, Bissonnette, and Garcia (1990). Four months later, the couples were contacted by telephone to determine whether or not they were still dating.

In the previous article, Simpson et al. (1995) reported that empathic accuracy was most impaired in couples who (a) had closer relationships but (b) questioned the long-term stability of their relationships, and (c) evaluated highly attractive opposite-sex persons as potential dating partners. The current study differs from the 1995 investigation in four significant ways. First, 
the 1995 study tested an entirely different set of predictions about the personal and situational factors that might be associated with reduced empathic accuracy (i.e., motivated inaccuracy) in a relationship-threatening situation. In contrast, the present study sought to determine whether highly anxious individuals might counter this general trend and display increased empathic accuracy in the same relationship-threatening situation. Second, in the present study, we test four new predictions derived from attachment theory, the appraisal model of trust, and Ickes and Simpson's (1997) model of empathic accuracy. None of these predictions were proposed or tested in the 1995 study. Third, guided by these new predictions, we coded several new behavioral measures from the videotapes and incorporated them into the original data set for the present analyses. We also constructed new content measures of each participant's thoughts and feelings during the experimental task. Fourth, in contrast to the 1995 study, the data analyses in the current investigation treat the individual rather than the couple as the primary unit of analysis. To our knowledge, the present study is the first to link attachment theory to empathic accuracy and the attachment-relevant behaviors that individuals display when their relationships are threatened by potential alternative partners.

\section{Method}

\section{Participants}

Eighty-two heterosexual dating couples (82 women and 82 men) participated in a study of "attraction and relationships." At least one member of each couple was enrolled in introductory psychology at Texas A\&M University. The mean age of men and women was 19.4 years and 18.8 years, respectively. The mean length of the relationships was 16.5 months.

\section{Procedure}

Phase 1. The male and female members of each couple first completed a large battery of self-report questionnaires in separate rooms. The participants were assured that their partner would not be allowed to see any of their answers, and they were instructed to answer all questions as accurately and honestly as possible. Partners first indicated how long they had dated each other and whether or not they were dating each other exclusively. They then completed the Collins and Read (1990) adult attachment scale, and Aron et al.'s (1991) single-item measure of subjective closeness (the IOS Scale). ${ }^{2}$ The subjective closeness measure was administered both 
immediately prior to and following the laboratory task to assess pre-to-post changes in each partner's perception of the closeness of their relationship.

For purposes described elsewhere (Simpson et al., 1995), the participants also completed five measures that assessed the perceived quality of their relationship: the Relationship Closeness Inventory (RCI: Berscheid et al., 1989), the Love Scale (Rubin, 1970), the Satisfaction Index (Simpson, 1987), the Commitment Scale (Rusbult, 1980), and the Investment Scale (Rusbult, 1980). Principal axis factor analyses (SPSS PA2), conducted separately for men and women, revealed that all five measures loaded highly on a single factor for both sexes. Thus, we transformed each measure into a common metric (using $z$-scores) and aggregated the five measures to form a single composite index of global relationship quality. Participants also completed the Trust Scale (Rempel, Holmes, \& Zanna, 1985) and an item that assessed which partner - the male or the female — was more dependent in each relationship. Specifically, this item asked "Who is more dependent on the relationship?" (anchored $1=I$ am more $\ldots$ and $7=$ My partner is more...).

The Collins and Read attachment scale is composed of 18 items answered on 5-point Likert-type scales (anchored $1=$ not at all characteristic of me and $5=$ very characteristic of me). Most of the items come from sentences contained in Hazan and Shaver's three original attachment vignettes. The Collins and Read scale was originally designed to assess three attachment themes: comfort with closeness, dependency, and anxiety. Recent psychometric work by Griffin and Bartholomew (1994a, 1994b), however, has revealed that two stable factors underlie the three categories. These factors correspond very closely to Bartholomew and Horowitz s (1991) View of Self versus View of Others dimensions. A principal axis factor analyses (SPSS PA2) followed by varimax rotation confirmed that these two dimensions underlie the Collins and Read scale. ${ }^{3}$

The first dimension (on which the closeness and dependency subscales load highly) has been labeled Avoidance (see Brennan, Clark, \& Shaver, 1998). It measures the extent to which individuals have positive versus negative views of significant others. People with higher scores on this dimension are comfortable with closeness and are willing to depend on others. These individuals tend to classify themselves as securely attached on the original Hazan and Shaver 
measure. In contrast, people with lower scores on the first dimension withdraw from closeness and eschew dependency in relationships. These individuals typically classify themselves as avoidantly attached on the Hazan and Shaver measure. Similar to previous research (e.g., Griffin \& Bartholomew, 1994a, 1994b), the internal consistency of the items that form this dimension was good for both the men (alpha $=.73)$ and the women $($ alpha $=.79)$ in the present sample.

The second dimension (on which the anxiety subscale loads highly) has been labeled Anxiety (see Brennan et al., 1998). It reflects the extent to which people have positive versus negative views of themselves in close relationships. People who score higher on this dimension have conflicted and ambivalent thoughts and feelings about their value as relationship partners and they are uncertain about whether others can be counted on in times of need. People who score lower have high and sometimes inflated views of their self-worth (see Griffin \& Bartholomew, 1994a, for more information on this two-dimensional factor structure). Previous research with large samples indicates that this dimension is internally consistent (typical alphas range from .70 to .75: see Griffin \& Bartholomew, 1994a). In our smaller sample, the internal consistency of the second dimension was slightly lower (alphas $=.60$ for each sex). The anxiety and avoidance dimensions served as our measures of attachment orientation.

Phase 2. Once both partners had completed the questionnaires, they were reunited and led to an experimental room containing a table, a slide projector, two chairs, and a viewing screen. They sat side-by-side in the two chairs, which were situated about 18 inches apart and faced a front-projected viewing screen. The experimenter then read the following instructions:

The next phase of this study involves rating photographs of individuals who have agreed to take part in a dating study. We already have several personality measures from our volunteers, but we need ratings of their physical attractiveness and sexual appeal. We are asking dating couples to make these ratings because you, in effect, are experts on dating. Due to the delicate nature of arranging dates, we want to be as confident of our matches as possible. Later this semester, we may ask you to conduct interviews with our dating study volunteers. In the event you are asked, we would arrange for you to privately interview one of your two most highly rated individuals.

The experimenter emphasized that it was crucial for both partners to provide honest, accurate ratings of each stimulus person. The couples then viewed twelve slides depicting six 
male and six female undergraduates. Couples randomly assigned to the Higher Threat condition saw twelve individuals who were highly attractive. In reality, these individuals were college-age professional models. Couples randomly assigned to the Milder Threat condition saw twelve individuals who were somewhat less attractive. The pictures of these individuals were taken from a college yearbook at a different university. ${ }^{4}$ Within each condition, the order of viewing (male partners rating slides of women first versus female partners rating slides of men first) was counterbalanced. Because the order in which the ratings were made did not affect the results, the rating order variable will not be discussed further.

Both partners rated all opposite-sex persons on their physical attractiveness and sexual appeal. When the slide depicting each stimulus person appeared on the screen, the experimenter asked the opposite-sex dating partner, "How physically attractive do you find this person to be as a potential dating partner?" and "How sexually appealing do you find this person to be as a potential dating partner?" Both questions were answered on 10-point scales, anchored $1=$ not at all and $10=$ extremely. After each partner stated his/her ratings out loud, the partners were given an opportunity to discuss what they liked or disliked about each person for approximately 30 seconds. Their interaction was covertly videotaped by a concealed camera mounted in the corner of the room. Following the study, we aggregated the twelve ratings (six physical attractiveness ratings plus six sexual appeal ratings) made by each dating partner to create a global index of the stimulus persons' rated physical attractiveness/sexual appeal. This global attractiveness index was highly reliable, with Cronbach alphas of .96 and .95 for the male and female dating partners, respectively.

When the rating task was finished, the participants completed a 3-item manipulation check measure that assessed how threatened they felt during the rating task. Specifically, using 9-point Likert-type scales anchored $1=$ not at all and $9=$ extremely, participants indicated the degree to which they felt threatened, jealous, and upset while their partner did the rating task. Responses were aggregated into a composite manipulation check measure of perceived threat, Cronbach alpha $=.90$. The correlation between partners on this measure (i.e., the within-dyad correlation) was $.25, p<.05$. Each partner then completed the Aron et al. (1991) subjective closeness measure a second time to assess changes in perceptions of closeness to their dating 
partner. The correlation between the partner's Time 2 closeness scores after their Time 1 closeness scores were partialed out was -.11, ns.

All couples then were informed that they had been videotaped during the rating task. The experimenter explained that they were not told about the videotaping before the study because such knowledge might have led them to interact in an unnatural or an atypical manner. Following this explanation, both partners were asked to give their informed consent for their videotapes to be released for research purposes. It was made clear that if either partner did not want the tape used for any reason, it would be erased immediately. No couple decided to do so. Participants were then informed that the individuals they rated were not involved in a local dating pool, and that neither partner would actually meet the person they rated most highly. They also were reassured that their partners would not be allowed to see any of their answers to either the questionnaires or to the thought/feeling tasks they would be asked to complete in the next phase of the study (Phase 3). We gave participants this debriefing information so they could focus their attention on, and provide more accurate data for, the Phase 3 thought/feeling tasks.

Phase 3. In Phase 3, the participants were led to separate rooms, both of which contained a VCR and a color monitor. Here they each viewed a separate copy of the videotape of the rating-and-discussion session they had just completed. Following procedures used in previous empathic accuracy studies (e.g., Stinson \& Ickes, 1992), participants were instructed to provide an accurate, honest, and complete account of all the thoughts and feelings they had during the rating-and-discussion task. In addition, they were guaranteed that their partners would not see their actual thought and feeling entries. These procedures were designed to increase the likelihood that the thoughts and feelings reported were accurate and candid.

The participants independently viewed the tape of their rating-and-discussion session twice. During the first viewing, both partners were asked to watch the videotape and to stop it when they remembered having had a specific thought or feeling at that moment in the interaction. Following a procedure developed by Ickes et al. (1990), participants were instructed to: (1) write down each thought or feeling on a standardized form; (2) indicate the number of minutes and seconds into the interaction when each thought or feeling occurred (using a timer displayed on the VCR); (3) specify whether each entry was a thought or a feeling; and (4) 
indicate whether each entry was positive, neutral, or negative in its emotional tone. The participants were reminded once again that their partners would not be shown any of their responses. The experimenter stayed in each room long enough to confirm that each partner followed the procedure correctly, at which point she left. The men recorded a mean of 12.7 thought/feeling entries (range $=5$ to 30 ), and the women recorded a mean of 11.8 entries (range $=$ 2 to 28$)$.

After finishing the thought/feeling reporting task, both partners were given a second set of thought/feeling forms containing only the times during which their partner reported having had specific thoughts or feelings (without revealing what those thoughts and feelings were). During the second viewing of the videotape, both partners were instructed to: (1) write down what they thought their partner had been thinking or feeling at each of the times specified; (2) indicate whether each inferred entry was a thought or a feeling; and (3) rate or judge its emotional tone.

After they had completed this thought/feeling inference task, both partners were thanked for their participation, after which they were fully and very carefully debriefed. The debriefing sessions lasted about thirty minutes, on average, and were specially designed to compensate for any personal and relational distress the dating partners may have experienced. The participants were reminded that the individuals they rated were not part of a "dating pool," and that the study actually concerned their cognitive and behavioral reactions when they and their partner evaluated opposite-sex persons as potential dating partners. The reason for the unobtrusive videotaping was more fully explained, and it was reiterated that the videotapes would be viewed only by trained research assistants. No couple was allowed to leave the debriefing session until the experimenter was convinced that both partners felt good about participating in the study and understood why various procedures had been used.

Phase 4. Approximately 4 months later, we attempted to contact all participants by telephone. Both members of 79 dyads ( $96.3 \%$ of the original sample) were successfully reached. Participants answered a brief telephone survey concerning their current dating status. In particular, they were asked: "When you participated in the study last fall, you were dating a person named [name of dating partner]. Are you still dating this person? (answered either "Yes" or "No"). Both partners had to agree about the current status of their relationship (still dating 
versus no longer dating) for their data to be used on this follow-up measure. Only one couple failed to agree about whether they were still dating.

\section{Construction of the Dependent Measures}

Empathic accuracy measure and covariates. Empathic accuracy was operationally defined as the degree to which one dyad member's written inference about the specific content of each of his or her partner's written thought/feeling entries matched the partner's actual content. Specifically, six independent judges (blind to all variables in the study) compared the written content of each actual entry with the corresponding inferred entry. The judges then rated the degree of similarity (i.e., the content accuracy) between each actual thought or feeling and each inference on a 3-point scale that ranged from 0 (essentially different content), through 1 (somewhat similar, but not the same, content), to 2 (essentially the same content). The internal consistency of this measure (where raters were treated as items) was .93. We then computed the mean of the six judge's similarity ratings for each actual-compared-with-inferred thought/feeling entry. These means were summed across all of the actual/inferred entry pairs within a given participant's protocol. The summed values were then divided by the maximum number of accuracy points that could be obtained for a given number of actual/inferred entry pairs. This was done to calculate an overall accuracy score that controlled for individual differences in the number of entries/inferences reported. This resulted in a global accuracy score that was scaled to range from .00 (total inaccuracy) to 1.00 (perfect accuracy).

To establish a baseline measure of empathic accuracy (which was designed to control for chance accuracy effects), a different set of six independent judges (also blind to all variables) then made similarity ratings of randomly paired actual/inferred thought/feeling entries within the protocols of each dyad. The internal consistency of this baseline measure was .83. A revised measure of empathic accuracy was then computed by subtracting the baseline accuracy score for each participant (i.e., perceiver) from his or her original global accuracy score. This adjusted measure represents the degree of empathic accuracy of each perceiver that remains after removing the baseline component, which estimates the degree of accuracy expected by chance. The interpartner correlation for this adjusted measure was .20, ns. This adjusted measure of 
empathic accuracy served as the dependent measure in the empathic accuracy analyses reported below.

We also constructed measures of two theoretically-relevant covariates: (a) the level of stress associated with each thought or feeling reported by each participant during the slide rating task (rated by four independent coders), and (b) the relative ease versus difficulty of inferring each thought or feeling from each participant's verbal and nonverbal behavior on the videotape (also rated by four independent coders who were blind to all variables). (For more details regarding these measures and their reliabilities, see Simpson et al., 1995).

Behavioral distress measure. Seven different independent coders (blind to all variables) then viewed the videotape of each couple's interaction. They rated the degree to which (a) each female partner appeared to be distressed when her male partner was rating slides of women, and (b) each male partner appeared to be distressed when his female partner was rating slides of men. Using 9-point Likert-type scales (anchored $1=$ not at all and $9=$ extremely), coders rated the behavior of men and women on seven dimensions: the extent to which each participant appeared (1) emotionally stressed, (2) uncomfortable, (3) annoyed, (4) threatened, (5) awkward, (6) upset, and (7) jealous when his/her partner was rating the stimulus persons. Interrater reliabilities for each item were good (individual item reliabilities ranged from .74 to .83). Principal axis factor analyses (SPSS PA2) conducted separately on men and women revealed that all seven items loaded a single factor for both sexes. Thus, they were aggregated into a behavioral distress index $($ Cronbach alphas $=.98$ for each sex $)$. The correlation between partners on this measure was $.63, p<.001$.

Partner checking measure. Another set of three independent coders (blind to all variables) then rated the frequency with which participants "checked on" their partner during the slide rating task. Checking was operationally defined as clear attempts by the partner who was rating the slides to see if his/her dating partner was comfortable with the task or needed reassurance. Examples of checking included actions such as looking at the partner and asking whether s/he was "okay", glancing at the partner and then touching him or her in a reassuring manner, and so on. Coders counted the number of times the partner who was rating the oppositesex stimulus persons checked on his/her partner. The reliability of this index was .76. Therefore, 
the coders' scores were averaged to form a global index of partner checking. The interpartner correlation for this measure was .12, $n s$.

Thought/feeling measures. A different set of five coders (blind to all variables) then read the content of the thoughts and feelings listed by each partner (blind to the content of his/her dating partner's thoughts and feelings) when the dating partner had been rating the opposite-sex stimulus persons. Guided by attachment theory, ratings of the thought/feeling content were made on eight dimensions: (1) evidence of distress or discomfort, (2) lack of self-confidence, (3) derogation of the stimulus persons, (4) perceptions of being "better than" the stimulus persons, (5) comparing the self to the stimulus persons, (6) focusing on the partner/relationship, (7) experiencing threat or jealousy, and (8) experiencing distrust of the partner. Each dimension was rated on 9-point Likert-type scales, anchored $1=$ not at all and $9=$ extremely $/$ a great deal .

Interrater reliabilities for each item were good (individual item reliabilities ranged from .71 to .89). Principal axis factor analyses (SPSS PA2) conducted separately on the thought/feeling content ratings of men and women revealed that items $1,2,5,7$, and 8 loaded highly on one factor within each sex. These items were aggregated to create an index of distressing/low selfconfidence thoughts and feelings (Cronbach alphas $=.87$ for each sex). Higher scores on this index indicated greater distress and less self-confidence. The interpartner correlation for this measure was $.31, p<.01$. The three items that did not load on a factor were retained as singleitem measures.

Finally, coders counted the number of times each partner failed to list an inference for a specific thought or feeling reported by their partner (i.e., when participants did not report a requested inference on the thought/feeling protocol or reported "I don't know"). Because the experimenter confirmed that each participant fully understood and could do the inference task before they completed it, failed inferences should indicate that participants either (a) had no idea what their partner was thinking or feeling at that point in the interaction or (b) did not want to make an inference about what their partner was thinking or feeling. For each participant, the number of failed inferences was divided by the total number of thoughts and feelings reported by his/her partner, resulting in an index of the proportion of failed inferences. The interpartner correlation for this measure was $.34, p<.01$. 


\section{Results}

We first calculated interpartner correlations for the two attachment dimensions to determine whether statistical dependency existed within the dyads. In line with previous research (e.g., Griffin \& Bartholomew, 1994a, 1994b; Simpson et al., 1992; Simpson et al., 1996), the partners' scores on both attachment dimensions were not correlated, average $r=-.04, n s$. Moreover, the men and women did not differ in their mean scores on either attachment dimension, both $t s<1, n s$. In addition, participants' attachment scores never interacted significantly with their partners' attachment scores in any of the analyses reported below. Following the recommendations of Kenny (1988) and Kenny and La Voie (1985), and given that our predictions were derived for individuals rather than for couples, the individual was treated as the unit of analysis. All variables were centered before the analyses were conducted (Aiken \& West, 1991). The reader should note that all significant and all marginally significant effects that emerged for both sexes are reported below.

Correlations between the two attachment dimensions and the Trust Scale (Rempel et al., 1985) confirmed relations found in previous research (e.g., Brennan \& Shaver, 1995). Within each sex, higher scores on the anxiety attachment dimension (i.e., greater anxious attachment) were associated with less trust ( $r \mathrm{~s}=-.26$ for men and -.31 for women, both $p s<.05$ ), whereas lower scores on the avoidance dimension (i.e., greater security) were associated with more trust $(r s=.26$ for men and .27 for women, both $p s<.05)$.

When we conducted the tests of our predictions that are reported below, we partialed the participants' scores on the Trust Scale from their scores on both attachment dimensions. We performed these analyses to determine whether the attachment dimensions explained variance in the dependent measures above and beyond that accounted for by relational trust. If, as we suspect, the anxiety attachment dimension is primarily responsible for the hypothesized effects, these effects should generally remain significant even when participants' scores on relational trust are statistically controlled. In additional analyses, we also partialed out scores on the global relationship quality index to discount the possibility that the quality of the partners' dating relationships accounted for any attachment effects.

\section{Manipulation Checks}


The first set of analyses checked on the effectiveness of the threat manipulation. As expected, males from couples who evaluated attractive alternatives reported more threat on the perceived threat index $(M=8.09)$ than did males from couples who evaluated less attractive alternatives $(M=5.43), t(80)=2.28, p<.03$. Similarly, females from couples who evaluated attractive alternatives reported more threat $(\mathrm{M}=7.31)$ than did females from couples who evaluated less attractive alternatives $(\mathrm{M}=4.75), t(80)=2.44, p<.02$.

We then examined participants' aggregated ratings of the physical attractiveness and sexual appeal of the six stimulus persons whom they evaluated in the slide rating task. Male partners who viewed more attractive women rated them higher $(M=6.47)$ than did males who viewed less attractive women $(\mathrm{M}=3.01), t(79)=15.10, p<.0001$. Similarly, female partners who evaluated more attractive men rated them higher $(M=6.28)$ than did females who evaluated less attractive men $(\mathrm{M}=3.07), t(79)=12.65, p<.0001$. Thus, the threat manipulation was successful for both sexes. ${ }^{5}$

\section{Gender Differences in the Manipulation Check and Dependent Measures}

Before testing our primary predictions, we conducted matched-pairs $t$-tests to test for gender differences in both the manipulation check measures and the dependent measures. The results revealed that men and women differed significantly on four indexes: behavioral distress, distressing thoughts and feelings, empathic accuracy, and differential dependence.

On the behavioral distress index, women were rated as being more visibly distressed during the rating task than were their male partners, matched-pairs $t=-2.19, p<.04$. However, on the distressing thoughts/feelings index, men reported thoughts and feelings that expressed greater distress and less self-confidence than did women, matched-pairs $t=3.92, p<.001$. Although men and women did not differ in their mean level of empathic accuracy, the men were significantly more accurate than the women in the higher threat condition, matched-pairs $t=$ $2.19, p<.04$. Conversely, women were significantly more accurate than men in the milder threat condition, matched-pairs $t=-2.17, p<.04$. On the differential dependence index, men indicated that they were the less dependent partner in their relationship; agreeing with them, women indicated that they were the more dependent partner, matched-pairs $t=2.89, p<.005$. 
To test our major predictions, we conducted two types of hierarchical regression analysis on each dependent measure. In the first set of analyses (conducted in SPSS-X), predictions were tested within each sex using standard regression procedures, and the variance associated with the individuals' grouping into particular dyads (dating couples) was not considered. In the second set of analyses (conducted in SAS), the same predictions were tested for all participants (males and females) combined, after first partialing out the effect of dyad membership. ${ }^{6}$ This procedure requires specifying in SAS that the covariate - the randomly assigned ID codes for the various dyads - should be treated as a class (i.e., categorical) variable. The resulting "dyad-adjusted" regression analysis enabled us to determine if the effect of our predictor (e.g., anxious attachment) generalized across both the male and the female participants, after controlling for the fact that they were grouped into particular dyads. If the main effect of a predictor variable is significant, but the predictor $\mathrm{X}$ gender interaction is not, there is evidence for the cross-gender generality of an effect.

Unless otherwise noted, the first set of analyses (i.e., the within-sex regressions) had the same format. Specifically, the threat condition to which couples were randomly assigned (coded dichotomously) was entered in Step 1, the two attachment dimensions were entered as a block in Step 2, and the two threat by attachment interaction terms were entered in Step 3. The second set of analyses (i.e., the cross-sex, "dyad-adjusted" regressions) were identical to the first set except that (a) couple ID number (treated as a class variable) was partialed out prior to Step 1 and (b) all interaction terms involving gender also were tested. The reader should note that because both the threat condition to which the couples were assigned and their dating status at the 4-month followup were between-dyad (as opposed to within-dyad) variables, we could not use the dyad-adjusted regression analyses to test for effects involving either of these variables. The reason, of course, is that the dyad-adjusted analyses partial out all of the variance at the between-dyad level before testing the remaining, individual-difference level effects.

Empathic accuracy. The first prediction (H1) was that more anxious individuals should display greater empathic accuracy than less anxious individuals during the relationshipthreatening rating-and-discussion task. To test this prediction, the empathic accuracy index was treated as the dependent variable. Although no significant effects emerged for men, two main 
effects were found for women. Women in the higher threat condition were significantly less accurate $(\mathrm{M}=7.78)$ than women in the milder threat condition $(\mathrm{M}=16.66)$, Beta $=-.41, t=-$ $3.92, p<.001$. However, countering this trend, women who scored higher on the anxiety attachment dimension (i.e., more anxious women) displayed significantly greater empathic accuracy across both the milder threat and the higher threat conditions, Beta $=.26, t=2.51, p<$ .02. In addition, when the dyad-adjusted regression analysis was conducted on all participants (men and women) combined, a significant main effect emerged for the anxiety attachment dimension, $\mathrm{F}(1,73)=5.44, \mathrm{p}<.03$, which was not qualified by gender, $\mathrm{F}<1, n s$.

To determine whether this effect might be attributable to confounding factors (see Schroder, Driver, \& Streufert, 1967), we conducted additional regression analyses in which the following three measures were partialed out prior to performing the standard hierarchical regressions: (a) coders' ratings of the amount of stress and tension evident in the female partners' thoughts and feelings, (b) coders' ratings of the ease with which the male partners' thoughts and feelings could be inferred from their behavior during the interaction, and (c) the female partners' self-reported level of trust. When each of these variables were partialed out, highly anxious women still exhibited greater empathic accuracy than did less anxious women, all Betas $>.18$, all $t s>1.81$, all $p s<.08$.

In summary, consistent with our first prediction, the greater empathic accuracy of highly anxious individuals appears to be driven by their strong, dispositionally-based need to accurately infer their partners' thoughts and feelings in this relationship-threatening situation. The fact that this effect was somewhat weaker for highly anxious men than for highly anxious women must be interpreted in the context of significant interaction effects (to be reported below). As we shall see, these interaction effects reveal that greater empathic accuracy is associated with greater relational instability for both highly anxious men and women.

Perceived threat/distressing thoughts and feelings. The second prediction (H2) was that, during the relationship-threatening task, more anxious individuals should (a) feel more threatened and (b) experience more distressing thoughts and feelings than their less anxious counterparts, especially in the higher threat condition. When the perceived threat index was the dependent variable, two main effects emerged for men. As reported earlier, men in the higher 
threat condition felt more threatened than did men in the milder threat condition, Beta $=.25, t=$ 2.28, $p<.03$. Furthermore, men who scored higher on the anxiety dimension (i.e., more anxious men) felt more threatened than did less anxious men, Beta $=.28, t=2.61, p<.02$. When men's scores on the Trust Scale were partialed out, both main effects remained significant, Betas $=.27$ and $.24, t \mathrm{~s}=2.51$ and $2.17, p s<.05$, respectively.

As reported earlier, women in the higher threat condition also perceived more threat than did women in the milder threat condition, Beta $=.26, t=2.44, p<.02$. Moreover, highly anxious women felt more threatened than less anxious women, although this effect was only marginally significant, Beta $=.20, t=1.81, p<.08$. In addition, one significant interaction emerged, indicating that women who scored lower on the avoidance dimension (i.e., more securely attached women) reported greater perceived threat, but only if they were in the higher threat condition, $t=3.35, p<.002$. Similar to men, when the women's scores on the Trust Scale were partialed out, all effects remained either significant or marginally significant (for the threat main effect, Beta $=.26, \mathrm{t}=2.40, \mathrm{p}<.05$; for the attachment anxiety main effect, Beta $=.21, t=1.81, p$ $<.08$; for the interaction, $t=3.32, p<.002$ ). Moreover, the dyad-adjusted regression analysis again revealed a significant main effect for the anxiety attachment dimension in the data for all participants (men and women) combined, $\mathrm{F}(1,76)=8.35, \mathrm{p}<.005$, which was not further qualified by gender, $\mathrm{F}<1, n s$.

The distressing thought/feeling index served as the dependent variable in the next set of analyses. For men, one significant and one marginally significant main effect emerged. Men in the higher threat condition reported thoughts and feelings that were rated as expressing greater distress and less self-confidence $(M=106.16)$ than those reported by the men in the milder threat condition $(\mathrm{M}=83.64)$, Beta $=33, t=3.01, p<.005$. Moreover, men who scored higher on the anxiety attachment dimension (i.e., more anxious men) reported more distressing and less selfconfident thoughts and feelings than did less anxious men, Beta $=.19, t=1.71, p<.10$, although this finding was only marginally significant.

For women, two main effects emerged. Similar to men, women in the higher threat condition reported thoughts and feelings that were rated as expressing greater distress and less self-confidence $(M=106.51)$ relative to women in the milder threat condition $(M=74.93)$, Beta 
$=.48, t=4.76, p<.0001$. Moreover, women who scored higher on the anxiety attachment dimension (i.e., more anxious women) reported more distressing and less self-confident thoughts and feelings than did less anxious women, Beta $=.23, t=2.25, p<.03$. This effect remained marginally significant when the women's scores on the Trust Scale were partialed out, Beta = $.19, t=1.77, p<.09$. When the dyad-adjusted regression analysis was performed on all participants (men and women) combined, a marginally significant main effect emerged for the anxiety attachment dimension, $\mathrm{F}(1,68)=3.65, \mathrm{p}<.07$, which was not qualified by gender, $\mathrm{F}<$ $1, n s$.

In summary, consistent with our second prediction, highly anxious men and women experienced greater threat and distress than their less anxious counterparts in response to the relationship-threatening task, and these effects were not attributable to individual differences in relational trust.

Changes in subjective closeness. The third prediction (H3) was that more anxious individuals should report at least temporary declines in the closeness of their relationships after the relationship-threatening interaction, especially in the higher threat condition. To test this prediction, we partialed out each partner's pre-experiment scores on Aron et al.'s (1991) subjective closeness measure (the IOS Scale) before conducting our standard 3-step regression analyses. Partners' post-experiment scores on the IOS Scale served as the dependent variable. This partialing procedure is preferable to using raw difference scores to estimate change because difference scores often have low reliabilities and they can confound actual change with the mean level of initial pre-test scores (see Cohen \& Cohen, 1983). For men, no main effects were found; however, a significant attachment anxiety by threat interaction emerged, $t=2.20, p<.04$. Specifically, men who scored higher on the anxiety dimension (i.e., more anxious men) and were assigned to the higher threat condition reported small yet significant declines in subjective closeness. This interaction remained significant when the men's scores on the Trust Scale were partialed out, $t=2.06, p<.05$.

For women, a single main effect emerged. Women who scored higher on the anxiety dimension (i.e., more anxious women) reported larger decrements in subjective closeness than did their less anxious counterparts, Beta $=-.10, t=-3.19, p<.004$. This effect also remained 
significant when the women's scores on the Trust Scale were partialed out, $t=3.10, p<.005$. On the other hand, when the dyad-adjusted regression analysis was conducted on all participants (men and women) combined, a non-significant trend for attachment anxiety was found, F $(1,70)$ $=2.15, n s$. This pattern of data indicates that the significant decrease in subjective closeness occurred for more anxious women in both the mild threat and the high threat conditions, but it emerged for highly anxious men in the high threat condition only.

It is important to emphasize that, while statistically significant, these drops in subjective closeness were small in magnitude and occurred for only some of the participants. In the full sample, the men's average score on subjective closeness was 5.40 prior to the interaction task and 5.39 following the interaction; in the full sample of women, the corresponding mean scores were 5.22 and 5.26. Regarding the main effect for attachment anxiety, women who scored above the median on the anxiety dimension (i.e., more anxious women) experienced a decline from 5.16 (pre-interaction) to 5.08 (post-interaction), reflecting an effect size (Cohen's d) of approximately .15. Conversely, women who scored below the median on the anxiety dimension experienced a slight increase in subjective closeness from 5.27 (pre-interaction) to 5.40 (postinteraction), reflecting an effect size of approximately .33. The attachment anxiety main effect, therefore, was attributable to the fact that (a) women who scored higher in anxiety experienced slight decrements in subjective closeness whereas (b) women who scored lower in anxiety experienced slight increments in closeness.

In summary, consistent with our third prediction, highly anxious men and women reported declines in the subjective closeness of their relationships following the relationshipthreatening interaction. Although this effect was confined to the higher threat condition for men, it was not attributable to individual differences in relational trust.

Relationship stability. The fourth prediction (H4) was that more anxiousindividuals should have relationships that are more vulnerable to dissolution. Of the 79 couples contacted at the 4-month follow-up, partners in 78 relationships agreed about whether or not they were still dating. Sixty couples were still dating, and 18 had broken up. To test the relationship stability prediction, we conducted logistic regression analyses (separately for each sex), treating relationship status at follow-up (coded 1 if still dating and 0 if not) as the dependent variable. 
The threat condition to which partners were randomly assigned (i.e., rating more attractive vs. less attractive stimulus persons), which was entered in Step 1, was not associated with different rates of dissolution, $t<1$, ns. Thus, rating and discussing more attractive stimulus persons did not result in a higher breakup rate. For both sexes, a single main effect was found. Men and women who scored higher on the anxiety dimension (i.e., more anxious individuals) were less likely to be dating their partners at follow-up, $t s=2.87$ and 2.10 , respectively, both $p s<.05$. For men, the effect remained significant when their scores on the Trust Scale were partialed out, $t=$ 2.37, $p<.03$; for women, it did not, $t<1$, ns. The dyad-adjusted regression analysis could not be performed on the stability data because there was no within-dyad variance in the dependent variable (dating status); all of it was between-dyad variance.

In summary, consistent with our fourth prediction, more anxious individuals were significantly more likely to breakup during the 4-month follow-up period. This effect was evident for both sexes. For men, the greater breakup rate was not attributable to individual differences in relational trust. However, for women, trust in the partner was a stronger predictor of relationship dissolution than was anxious attachment.

\section{Anxious Attachment X Empathic Accuracy Interactions}

A major goal of the present study was to explore the hypothesized links between anxious attachment, empathic accuracy in a relationship-threatening situation, and subsequent relationship instability. Ickes and Simpson's (1997) model posits that low empathic accuracy can serve as a buffer against negative relationship outcomes when relationships are threatened. If highly anxious-uncertain individuals tend to accentuate the negative implications of single, isolated relationship-threatening events whereas less anxious-uncertain individuals tend to overlook or downplay these events (Holmes \& Rempel, 1989), the consequences of accurately inferring their partner's thoughts and feelings should be more negative for highly anxious individuals. Specifically, if individuals are highly anxious about their relationship and they display heightened empathic accuracy in relationship-threatening contexts, they should be particularly susceptible to either decreases in subjective closeness (in the short-term) or relationship dissolution (in the long-term). This reasoning implies that the association between 
empathic accuracy and either changes in closeness or relationship dissolution should be moderated by individuals' level of attachment anxiety in relationship-threatening situations.

To examine this possibility, we conducted four analyses testing for these expected moderation effects (see Baron \& Kenny, 1986). The first set of regression analyses (conducted separately on women and men) treated each participant's post-interaction subjective closeness score on the IOS Scale as the dependent variable. Within each sex, each participant's experimental condition, pre-interaction score on subjective closeness, anxiety dimension score, avoidance dimension score, and empathic accuracy score was entered as a block in Step 1. The interaction term involving anxiety and empathic accuracy was entered in Step 2. A significant interaction did not emerge for the men, but one was found for the women, $t=3.42, p<.01$. It indicated that women who scored higher on the anxiety dimension and who displayed greater empathic accuracy reported feeling less close to their partner immediately after the rating-anddiscussion task, whereas women who scored lower on anxiety and were more empathically accurate reported feeling slightly closer to their partner. Thus, for women, the effect of empathic accuracy on changes in subjective closeness was moderated by their standing on the anxiety attachment dimension. When the dyad-adjusted analysis was conducted for all participants (men and women) combined, the anxiety $\mathrm{X}$ empathic accuracy interaction was significant, $\mathrm{F}(1,70)=$ $4.68, \mathrm{p}<.04$, and it was not qualified by gender, $\mathrm{F}<1, n s$ (see Figure 1 ).

[ Insert Figure 1 about here ]

The second set of regression analyses (also conducted separately on women and men) treated the dichotomously-coded relationship stability measure as the dependent variable. Within each sex, each participant's experimental condition, anxiety dimension score, avoidance dimension score, and empathic accuracy score was entered as a block in Step 1. The interaction term involving each participant's anxiety and empathic accuracy score was then entered in Step 2. A significant interaction did not emerge for women; relationship instability was predicted almost exclusively by women's scores on the anxiety attachment dimension. For men, however, a significant interaction was found, $t=2.19, p<.04$. Men who scored higher on the anxiety dimension and who displayed greater empathic accuracy were more likely to have had relationships that ended during the 4-month period, whereas men who scored lower on anxiety 
and who displayed greater empathic accuracy were less likely to have experienced relationship dissolution (see Figure 2). Thus, the effect of empathic accuracy on relationship stability for men was moderated by their standing on the anxiety attachment dimension. A dyad-adjusted regression analysis could not be applied to the stability data since there was no within-dyad variance in the dependent variable (dating status); all variance was between-dyads. [ Insert Figure 2 about here ]

\section{Effects for the Avoidance Attachment Dimension}

Although our major predictions focused on the anxious attachment dimension, we also analyzed and report the results for the avoidance dimension. We do so because the findings support and extend what Bowlby (1973) claimed and others have found regarding the defensive, withdrawn orientation of highly avoidant individuals in relationship-threatening situations (see Fraley, Davis, \& Shaver, 1998, for a review). Individuals who score higher on the avoidance dimension typically classify themselves as "avoidant" on the Hazan and Shaver (1987) attachment paragraphs, whereas those who score lower usually classify themselves as "secure." The pattern of effects reported below reveals the different behavioral, cognitive, and emotional strategies that more avoidant individuals used to distance themselves from the relationshipthreatening situation. However, highly avoidant men and women responded differently on the various measures involving avoidance or withdrawal tendencies. Because the dyad-adjusted analyses did not yield significant avoidant attachment effects for these measures that generalized across the male and female dating partners, the results of the dyad-adjusted regressions are not reported in this section.

Partner checking. According to attachment theory, more secure individuals should offer some situationally-appropriate sign of concern, support, or reassurance to their partners during the stressful task (see Simpson et al., 1992), perhaps by checking to see how their partners are coping with it. When the behavioral checking measure was treated as the dependent variable, a main effect for the avoidance dimension was found for the women but not for the men. Specifically, women who scored lower on the avoidance dimension (i.e., more securely attached women) checked more frequently to see if their partner was feeling distressed during the ratingand-discussion task, whereas women who scored higher (i.e., more avoidant women) checked 
less frequently, Beta $=.28, t=2.58, p<.02$. This effect remained significant when the women's scores on the Trust Scale were partialed out, Beta $=.27, t=2.47, p<.02 .^{7}$

Detachment from the partner/interaction. Attachment theory further suggests that more avoidant individuals should display more evidence of being detached from their partners during stressful interactions (see Bowlby, 1973; Crittenden \& Ainsworth, 1989; Fraley et al., 1998). According to Cassidy and Kobak (1987), detachment could be manifested either behaviorally (e.g., by appearing less distressed, by thinking about or checking on the partner less often) or cognitively (e.g., by failing to make inferences about the content of the partner's thoughts and feelings). A number of these "detachment effects" were found.

When the observer-rated behavioral distress index was the dependent measure, two main effects emerged for men. Men in the higher threat condition appeared more distressed $(\mathrm{M}=$ 231.91) than did men in the milder threat condition $(\mathrm{M}=188.14)$, Beta $=.46, t=4.60, p<.0001$. Furthermore, men who scored higher on the avoidance dimension (i.e., more avoidantly attached men) were rated as appearing less distressed than men who scored lower on it (i.e., more secure men), Beta $=.22, t=2.29, p<.03$. When the men's scores on the Trust Scale were partialed out, the main effect for avoidance remained significant, Beta $=.28, t=2.88, p<.01$. For women, one main effect was found. Women in the higher threat condition appeared more distressed $(M=244.76)$ than did women in the milder threat condition $(M=191.61)$, Beta $=.54$, $t=5.78, p<.0001$.

When the partner checking index served as the dependent measure, no main effect was found for men on the avoidance dimension. However, as reported above, more avoidant women checked less frequently than did more secure women to see if their partner was feeling distressed during the rating task, Beta $=.28, t=2.58, p<.02$.

In the next set of analyses, the single-item observer-rated measure of the degree to which participants' thoughts and feelings focused on their partner/relationship during the rating task was the dependent measure. Men who scored higher on the avoidance dimension (i.e., more avoidant men) had thoughts and feelings that focused less on their partner/relationship when she was rating other men compared to less avoidant (i.e., more secure) men, Beta $=.22, t=1.99, p=$ 
.05. When the men's scores on the Trust Scale were partialed out, this effect did not change, Beta $=.22, t=1.99, p=.05$.

Finally, when the proportion of failed inferences was the dependent measure, no effects were found for men. However, one significant and one marginally significant main effect emerged for women. Specifically, women who scored higher on the avoidance dimension (i.e., more avoidant women) had more failed (i.e., blank or "I don't know") inferences than did less avoidant (i.e., more secure) women, Beta $=.26, t=2.41, p<.02$. In addition, women who scored higher on the anxiety dimension (i.e., more anxious women) had a smaller proportion of failed inferences than did less anxious women, Beta $=.19, t=1.75, p<.09$, although this finding was only marginally significant. The main effect for the avoidance dimension remained significant when women's scores on the Trust Scale were partialed out, Beta $=.25, t=2.18, p<.04$.

In summary, the data for the avoidance attachment dimension were consistent with tenets of attachment theory. More avoidant men expressed their detachment during the rating-anddiscussion task by appearing less distressed and by reporting fewer partner-focused thoughts and feelings. More avoidant women, on the other hand, expressed their detachment by checking their partners' reactions less often and by failing to make inferences about what their partners were thinking or feeling. Once again, none of these effects was attributable to variance associated with the participants' trust scores. ${ }^{8}$

\section{Tests for Gender Interactions}

Were any of the attachment effects significantly larger or smaller for men versus women? To answer this question, we tested for evidence of significant gender interactions (Cohen \& Cohen, 1983). In the first analysis, for example, we tested to determine whether the significant main effect for women between the anxiety attachment dimension and empathic accuracy was significantly larger than the non-significant relation for men between these two variables. Because of statistical dependency between the partners' scores on some of the dependent variables, we used Cohen and Cohen's (1983, p. 56-57) test for the significance of the difference between dependent Betas for each dependent measure on which attachment effects emerged. This relatively conservative test revealed no significant attachment dimension $\mathrm{X}$ gender interactions for any of the dependent measures. Similarly, none of the more sensitive dyad- 
adjusted regression analyses revealed significant attachment dimension $\mathrm{X}$ gender interactions for any of the dependent measures.

\section{Discussion}

Conventional wisdom suggests that "greater understanding" is a sovereign remedy for the various ills that can plague close relationships. This belief is naive. As the present findings demonstrate, there are circumstances in which greater understanding (i.e., increased empathic accuracy) is associated with reduced feelings of closeness and with greater relationship instability. In relationship-threatening situations, anxiously attached individuals appear to be particularly vulnerable to the negative implications of their partners' thoughts and feelings. When highly anxious individuals attempt to "read" their partners in such situations, heightened empathic accuracy may be more of a curse than a blessing because it increases their feelings of threat and distress, reduces their feelings of closeness, and may increase the likelihood that their relationships will eventually dissolve.

\section{Summary of the Major Findings}

Integrating ideas from attachment theory (Bowlby, 1973; Cassidy \& Berlin, 1994), the theory of relational trust (Holmes \& Rempel, 1989), and our own model of empathic accuracy (Ickes \& Simpson, 1997), we tested five major predictions about how people with more anxious attachment orientations react when their relationships are threatened by alternative dating partners. Consistent with the first prediction (H1), high- versus low-anxious men and women were especially accurate (i.e., more hypervigilant) when they inferred their partners' thoughts and feelings during the relationship-threatening task. In addition, interaction effects (discussed below) revealed that both highly anxious men and women experienced greater relational instability when they more accurately "read" their partner's thoughts and feelings in the relationship-threatening situation. Consistent with the second prediction (H2), more anxious men and women reported feeling greater threat and distress during the rating-and-discussion task. Specifically, highly anxious men and women felt more threatened during the task, and their thoughts and feelings were rated as revealing greater discomfort and less confidence in themselves, their partner, and the relationship. 
Consistent with our third and fourth predictions (H3 and H4), when more anxious individuals accurately inferred their partners' thoughts and feelings in the relationship-threatening situation, they were more likely to experience relational instability and their relationships were more likely to have broken up by the 4-month followup. Finally consistent with our fifth prediction (H5), significant attachment anxiety by empathic accuracy interactions indicated that more anxious individuals who displayed greater empathic accuracy reported slight-but-significant declines in feelings of closeness to their partners, and that more anxious men who displayed greater empathic accuracy exhibited higher breakup rates at the 4-month follow-up. Perhaps the accumulation across time of inferences that their partners are attracted to other members of the opposite sex takes its toll on men's relational commitment sooner that it does on women's. This interpretation of why the second interaction was significant only for the men is speculative, but it is also consistent with findings from the evolutionary psychology perspective which have repeatedly shown that ETC...

The interactions reported in Figures 1 and 2 indicate that accurately inferring the partner's thoughts and feelings during the relationship-threatening task had negative relational consequences for more anxious individuals but positive consequences for those who were less anxious. People who score lower on the anxiety attachment dimension tend to have positive views of themselves as relationship partners, and they are usually classified as either secure or dismissive-avoidant on categorical attachment measures (see Bartholomew \& Horowitz, 1991). The interaction results suggest that less anxious individuals either avoid thinking about the negative implications of their partners' thoughts and feelings in relationship-threatening situations (perhaps in the case of dismissive-avoidant people) or simply discount any potential negative implications (perhaps in the case of secure people). Simpson and Rholes (1994) have proposed that individuals who score low on the anxiety dimension-especially more secure individuals, who also hold positive views of romantic partners - may use negative events as opportunities to strengthen commitment to their relationships. Recently, Simpson et al. (1996) have found that less anxious individuals report feeling closer to their partners after trying to resolve a major, relationship-based conflict with them. This constructive behavior contrasts 
sharply with that of highly anxious individuals in the present study, whose accuracy regarding their partners' potentially harmful thoughts and feelings led them to draw immediate negative inferences about the state of their relationship.

Additional findings for the avoidance dimension revealed that less avoidant (i.e., more securely attached) women checked to see how their partners were coping more often during the rating task than did highly avoidant women. Both more avoidant men and women expressed their detachment behaviorally, but in somewhat different ways. Avoidant men displayed fewer overt signs of distress than did less avoidant (i.e., more secure) men, and they reported fewer partner-focused thoughts and feelings during the relationship-threatening task. More avoidant women were less likely to check on their partners' reactions during the task, and they more often refrained from inferring the content of their partners' thoughts and feelings. All of these behaviors appear to serve the same functional goal - to minimize involvement in stressful situations that, if not managed, could activate their attachment system (see Bartholomew, 1990; Crittenden \& Ainsworth, 1989).

\section{Qualifications Based on Gender or Level of Situational Threat?}

In general, the findings were highly consistent with the five predictions derived from all three theoretical perspectives. One might ask, however, whether any gender-based qualifications are warranted. The simple answer is no. Not a single significant attachment dimension $\mathrm{X}$ gender interaction was found for any of the dependent measures in either type of regression analysis (either the within-sex regressions or the cross-sex, dyad-adjusted regressions).

But what about the level of situational (manipulated) threat? Should threat have interacted with the anxious attachment dimension, such that effects for highly anxious individuals were found only in the high threat condition? Probably not. The predictions about anxious attachment derived from Bowlby's (1969, 1973) and Cassidy and Berlin's (1994) accounts of attachment theory generally apply to any situation in which a meaningful degree of threat to the relationship is perceived. Indeed, what makes the behavior of anxiously attached individuals seem so dysfunctional is their tendency to perceive relationship threat in situations that most people would regard as benign and non-threatening. To identify contexts in which anxious attachment is likely to interact with situational threat, researchers must compare high 
threat experimental conditions with truly nonthreat conditions (instead of the mild threat condition used in the present study).

\section{Ethical Considerations}

Our speculations about relationship-maintenance motives raise the related issue of the ethical implications of this research. By subjecting dating partners to a laboratory task that presented some degree of situational threat to their relationships, did we do any lasting harm to these relationships that would not have occurred otherwise? Addressing this question in terms of the available data, at least three lines of evidence suggest that the experimental task did not augment the expected rate of relationship dissolution. First, couples who rated more attractive persons (those in the higher threat condition) were not more likely to breakup compared to couples who rated less attractive persons (those in the milder threat condition, $t<1$ ). Second, although more anxious women reported a statistically significant decline in subjective closeness immediately after the rating-and-discussion task, it was objectively small (approximately .10 units on the 7-point IOS Scale) and probably transient. Third, and most important, the breakup rate in this study (23\%) was actually lower than those of previous dating studies involving no experimental manipulations. For example, the breakup rate was $42 \%$ over 3 months in a study reported by Simpson (1987), and it was 33\% over 6 months in a study by Attridge, Berscheid, and Simpson (1995). The breakup rate for the most susceptible individuals in the present study - women who scored above the median on both attachment anxiety and empathic accuracy - was $32 \%$, slightly lower than what is normally found in dating couples over comparable periods of time in studies with no experimental interventions.

We believe that our relatively low breakup rate is attributable to the very careful and thorough debriefings we conducted. These debriefings, which typically lasted 30 minutes per couple, were carefully developed and pilot-tested to ensure that both partners would feel good about themselves, their partner, and their relationship before leaving the laboratory. In each debriefing session, we emphasized that each partner's response to the experimental task was "normal," that feeling some degree of distress was the typical response in this situation, and that exposure to the experimental procedures was necessary to help researchers better understand how relationships are maintained when they are confronted with external threats. 
Although the breakup rate data offer tangible evidence that harmful, long-term effects did not occur in this study, researchers must still decide whether the short-term distress caused by the experimental interventions was justified given the importance of the problems being investigated. Different researchers will inevitably arrive at different conclusions in this regard. Our own assessment is that we optimized the trade-off between two important goals: (a) studying the effects of a temporary relationship threat in a manner that was as naturalistic and externally valid as possible, and (b) minimizing the stress and discomfort experienced by the participants in our study. Having spent considerable time discussing the study with each couple during the debriefing sessions, we are confident that our debriefing procedures alleviated most if not all of the short-term distress that our experimental task may have induced.

\section{Implications for Theory and Application}

Why do highly anxious-uncertain individuals tend to have such turbulent and unstable relationships? The results of the present study provide some tentative answers to this question, answers that may have important theoretical and real-world implications.

Implications for attachment theory. The present findings have important implications for attachment theory. The empathic accuracy findings confirm that highly anxious individuals are, in fact, more "hypervigilant" when they must deal with a relationship-threatening situation (see Cassidy \& Berlin, 1994; Kobak \& Sceery, 1988; Mikulincer et al., 1993 for indirect evidence relevant to this prediction). Related findings also reveal how attachment anxiety interacts with empathic accuracy to destabilize the relationships of highly anxious individuals. Heightened empathic accuracy in relationship-threatening situations leads more anxious men and women to feel less close to their romantic partners, and it forecasts relationship dissolution in more anxious men. Although attachment theorists (e.g., Bowlby, 1973; Cassidy \& Berlin, 1994) have speculated about the proximate psychological processes that should destabilize the relationships of highly anxious individuals, this is the first study to demonstrate the operation of one significant process - the destabilizing impact of accurately "reading" a partner's thoughts and feelings in a relationship-threatening context.

An important question for future attachment research is: Why do highly anxious people tend to base their current perceptions of their partners/relationships on single, negative 
relationship events rather than viewing such events within the broader, long-term context of their entire relationships? Bowlby (1973) and Main (1991) have conjectured that highly anxious individuals have two "sets" of internal working models. The primary set, developed during childhood, contains a constellation of negative thoughts, feelings, memories, and expectations about how one will be treated by others. The secondary set, which develops during adolescence and adulthood, contains more positive components that reflect how one ideally hopes to be treated by others; this secondary set allows highly anxious people to experience at least moderate levels of relationship trust.

According to Bowlby, both sets of working models remain largely disconnected and isolated from each other. In non-stressful situations, the secondary set should guide how highly anxious people think, feel, and behave. When distressing situations are encountered (such as our rating-and-discussion task), the primary set should be activated, producing temporarily negative and disenfranchised views of the current partner/relationship. A contrasting view, proposed by Mikulincer (1995), posits that highly anxious people have only one set of interrelated, highly conflicted thoughts, feelings, memories, and expectations. According to this view, rapid, situationally-induced changes in perceptions of the partner/relationship should be governed by which component of an individual's working model is salient at a given point in time. Future research should determine which structure - the dual structure of working models or the unitary structure - best accounts for the relatively rapid, situation-specific perceptual changes often experienced by highly anxious people.

Implications for the theory of relational trust. Regarding the link between attachment theory and relational trust, the present findings reveal that the anxiety attachment dimension usually remained a significant predictor of the dependent measures when relational trust was statistically controlled. These findings suggest that the relationships of highly anxious individuals are volatile because of the inherent emotional volatility of these individuals (Tidwell, Reis, \& Shaver, 1996), and not because highly anxious individuals view their partners as untrustworthy. In the present study, only one of the many attachment effects was appreciably attenuated when trust was controlled: for women, trust may be more important than anxious attachment in affecting eventual relationship dissolution. 
Implications for Ickes and Simpson's empathic accuracy model. The present findings also suggest an important qualification to Ickes and Simpson's (1997) empathic accuracy model. Specifically, the predicted negative association between empathic accuracy and relational stability in relationship-threatening situations appears to hold true only for highly anxious individuals. This qualification suggests that Ickes and Simpson's model would benefit from greater conceptual integration with attachment theory. In particular, the model should be revised to acknowledge that different attachment orientations may dispose individuals to react differently when inferring their partner's thoughts and feelings in relationship-threatening contexts. Whereas highly anxious partners may suffer from a "hypervigilant" need to closely monitor their partner's thoughts and feelings, less anxious partners may not. And highly avoidant partners may simply tend to avoid making relationship-threatening inferences about their partner's thoughts and feelings.

Applied implications. Finally, the present findings may have important implications for how therapy should be conducted with couples in which at least one partner is highly anxious. Although enhancing empathic accuracy with respect to relationship-threatening issues might be good for many couples in therapy, training highly anxious people to become more accurate about such issues may - in the early stages of therapy_-do more harm than good. Because highly anxious individuals typically have immediate, negative reactions about the relationshipthreatening thoughts and feelings that might be harbored by their romantic partners, forcing them to confront such thoughts and feelings before they learn how to deal with them effectively could be a major therapeutic mistake. Instead of strengthening the couple's relationship, such an intervention could easily backfire and cause the relationship to become even more volatile and unstable. A better strategy would be to first train these couples to develop greater empathic accuracy with respect to benign, non-threatening issues, and then gradually encourage them to develop greater accuracy with regard to more divisive and threatening ones. 


\section{References}

Aiken, L. S., \& West, S. G. (1991). Multiple regression: Testing and interpreting interactions. Newbury Park, CA: Sage.

Aron, A., Aron. E. N., \& Smolan, D. (1990, July). Assessing closeness as including other in the self: The IOS Scale. Paper presented at the International Conference on Personal Relationships, Oxford, England.

Aron, A., Aron, E. N., Tudor, M., \& Nelson, G. (1991). Close relationships as including others in the self. Journal of Personality and Social Psychology, 60, 241-253.

Attridge, M., Berscheid, E., \& Simpson, J. A. (1995). Predicting relationship stability from both partners versus one. Journal of Personality and Social Psychology, 69, 254-268.

Baron, R. M., \& Kenny, D. A. (1986). The moderator-mediator variable distinction in social psychological research: Conceptual, strategic, and statistical considerations. Journal of Personality and Social Psychology, 51, 1173-1182.

Bartholomew, K. (1990). Avoidance of intimacy: An attachment perspective. Journal of Social and Personal Relationships, 7, 147-178.

Bartholomew, K., \& Horowitz, L. M. (1991). Attachment styles among young adults: A test of a four-category model. Journal of Personality and Social Psychology, 61, 226244.

Bentler, P. M., \& Newcomb, M. D. (1978). Longitudinal study of marital success and failure. Journal of Consulting and Clinical Psychology, 46, 1053-1070.

Berscheid, E., Snyder, M., \& Omoto, A. M. (1989). The Relationship Closeness Inventory: Assessing the closeness of interpersonal relationships. Journal of Personality_and Social Psychology, 57, 792-807.

Bolger, N., \& Schilling, E. A. (1991). Personality and the problems of everyday life: The role of neuroticism in exposure and reactivity to daily stressors. Journal of Personality, 59, $355-386$.

Bowlby, J. (1969). Attachment and Loss: Volume 1. Attachment. New York: Basic Books. 
Bowlby, J. (1973). Attachment and loss: Volume 2. Separation: Anxiety and anger. New York: Basic Books.

Bowlby, J. (1982). Attachment and Loss: Volume 1. Attachment (2 ${ }^{\text {nd }}$ ed.). New York: Basic Books.

Brennan, K. A., Clark, C. L., \& Shaver, P. R. (1998). Self-report measurement of adult attachment: An integrative overview. In J. A. Simpson \& W. S. Rholes (Eds.), Attachment theory and close relationships (pp. 46-76). New York: Guilford.

Brennan, K. A., \& Shaver, P. R., (1995). Dimensions of adult attachment, affect regulation, and romantic relationship functioning. Personality and Social Psychology Bulletin, $21,267-283$.

Cancian, F., \& Gordon, S. L. (1988). Changing emotional norms in marriage: Love and anger in U.S. women s magazines since 1900. Gender and Society, 2, 308-342.

Cassidy, J., \& Berlin, L. J. (1994). The insecure/ambivalent pattern of attachment: Theory and research. Child Development, 65, 971-991.

Cassidy, J., \& Kobak, R. R. (1987). Avoidance and its relation to other defensive processes. In J. Belsky \& T. Nezworski (Eds.), Clinical implications of attachment (pp. 300323). Hillsdale, NJ: Erlbaum.

Cohen, J. \& Cohen, P. (1983). Applied multiple regression/correlation analysis for the behavioral sciences. Hillsdale, NJ: Erlbaum.

Collins, N. L., \& Read, S. J. (1990). Adult attachment, working models, and relationship quality in dating couples. Journal of Personality and Social Psychology, 58, 644663.

Colvin, C. R., Vogt, D., \& Ickes, W. (1997). Why do friends understand each other better than strangers? In W. Ickes (Ed.), Empathic accuracy (pp. 169-193). New York: Guilford.

Crittenden, P. M., \& Ainsworth, M. (1989). Child maltreatment and attachment theory. In D. Cicchetti \& V. Carlson (Eds.), Child maltreatment: Theory and research on the causes and consequences of child abuse and neglect (pp. 432-463). Cambridge, England: Cambridge University Press. 
Feeney, J. A. (1998). Adult attachment and relationship-centered anxiety: Responses to physical and emotional distancing. In J. A. Simpson \& W. S. Rholes (Eds.), Attachment theory and close relationships (pp. 189-218). New York: Guilford.

Fraley, R. C., Davis, K. E., \& Shaver, P. R. (1998). Dismissive-avoidance and the defensive organization of emotion, cognition, and behavior. In J. A. Simpson \& W. S. Rholes (Eds.), Attachment theory and close relationships (pp. 249-279). New York: Guilford.

Funder, D. C. (1995). On the accuracy of personality judgment: A realistic approach. Psychological Review, 102, 652-670.

Gesn, P. R. (1997). The development of meaning contexts for empathic accuracy: Channel and sequence effects. Unpublished doctoral dissertation, University of Texas at Arlington.

Gonzalez, R., \& Griffin, D. (1997). On the statistics of interdependence: Treating dyadic data with respect. In S. Duck, K. Dindia, W. Ickes, R. Milardo, R. Mills, \& B. Sarason (Eds.), Handbook of personal relationships: Theory, research, and interventions (2nd ed., pp. 271-302). Chichester, UK: Wiley.

Griffin, D., \& Bartholomew, K. (1994a). Models of the self and other: Fundamental dimensions underlying measures of adult attachment. Journal of Personality and Social Psychology, 67, 430-445.

Griffin, D., \& Bartholomew, K. (1994b). The metaphysics of measurement: The case of adult attachment. In K. Bartholomew \& D. Perlman (Eds.), Attachment processes in adulthood. (pp. 17-52). London: Kingsley.

Hazan, C., \& Shaver, P. (1987). Romantic love conceptualized as an attachment process. Journal of Personality and Social Psychology, 52, 511-524.

Hazan, C., \& Shaver, P. (1994). Attachment as an organizational framework for research on close relationships. Psychological Inquiry, 5, 1-22.

Holmes, J. G. (1991). Trust and the appraisal process in close relationships. In W. H. Jones \& D. Perlman (Eds.), Advances in personal relationships, Vol. 2 (pp. 57-104). London: Kingsley. 
Holmes, J. G., \& Rempel, J. K. (1989). Trust in close relationships. In C. Hendrick (Ed.), Close relationships: Review of Personality and Social Psychology, Vol. 10 (pp. 187-220). Newbury Park, CA: Sage.

Ickes, W., \& Simpson, J. A. (1997). Managing empathic accuracy in close relationships. In W. Ickes (Ed.), Empathic accuracy (pp. 218-250). New York: Guilford. Ickes, W., Stinson, L., Bissonnette, V., \& Garcia, S. (1990). Naturalistic social cognition: Empathic accuracy in mixed-sex dyads. Journal of Personality and Social Psychology, 59, 730-742.

Jones, W. H., Couch, L., \& Scott, S. (1997). Trust and betrayal: The psychology of getting along and getting ahead. In R. Hogan, J. Johnson, \& S. Briggs (Eds.), Handbook of personality psychology (pp. 465-488). New York: Academic.

Josephs, R. A., Markus, H. R., \& Tafarodi, R. W. (1992). Gender and self-esteem. Journal of Personality and Social Psychology, 63, 391-402.

Kahn, M. (1970). Nonverbal communication and marital satisfaction. Family Process, 9, 449-456.

Karniol, R. (1990). Reading people's minds: A transformation rule model for predicting others' thoughts and feelings. Advances in Experimental Social Psychology, 23, 211247.

Kelly, E. L., \& Conley, J. L. (1987). Personality and compatibility: A prospective analysis of marital stability and marital conflict. Journal of Personality and Social Psychology, $52,27-40$.

Kenny, D. A. (1988). The analysis of data from two-person relationships. In S. Duck (Ed.), Handbook of personal relationships (pp. 57-78). London: Wiley.

Kenny, D. A. (1994). Interpersonal perception: A social relations analysis. New York: Guilford.

Kenny, D. A., \& La Voie, L. (1985). Separating individual and group effects. Journal of Personality and Social Psychology, 48, 339-348.

Kirkpatrick, L. A., \& Hazan, C. (1994). Attachment styles and close relationships: A four-year prospective study. Personal Relationships, 1, 123-142. 
Kobak, R. R., \& Sceery, A. (1988). Attachment in late adolescence: Working models, affect regulation, and representations of self and others. Child Development, 59, 135-146.

Main, M. (1990). Cross-cultural studies of attachment organization: Recent studies, changing methodologies, and the concept of conditional strategies. Human Development, 33, 4861.

Main, M. (1991). Metacognitive knowledge, metacognitive monitoring, and singular (coherent) vs. multiple (incoherent) models of attachment. In C. M. Parkes, J. Stevenson-Hinde, \& P. Marris (Eds.), Attachment across the life cycle (pp. 127-159). London: Tavistock/Routledge.

Mikulincer, M. (1995). Attachment style and the mental representation of the self. Journal of Personality and Social Psychology, 69, 1203-1215.

Mikulincer, M., Florian, V., \& Tolmatz, R. (1990). Attachment styles and fear of personal death: A case study of affect regulation. Journal of Personality and Social Psychology, 58, 273-280.

Mikulincer, M., Florian, V., \& Weller, A. (1993). Attachment styles, coping strategies, and post-traumatic psychological distress: The impact of the Gulf War in Israel. Journal of Personality and Social Psychology, 64, 817-826.

Noller, P. (1980). Misunderstandings in marital communication: A study of couples' nonverbal communication. Journal of Personality and Social Psychology, 39, 1135-1148.

Noller, P., \& Ruzzene, M. (1991). Communication in marriage: The influence of affect and cognition. In G. J. O. Fletcher \& F. D. Fincham (Eds.), Cognition in close relationships (pp. 203-233). Hillsdale, NJ: Erlbaum.

Pistole, M. C. (1989). Attachment in adult romantic relationships: Style of conflict resolution and relationship satisfaction. Journal of Social and Personal Relationships, 6, $505-510$.

Rempel, J. K., Holmes, J. G., \& Zanna, M. P. (1985). Trust in close relationships. Journal of Personality and Social Psychology, 49, 95-112.

Rubin, Z. (1970). Measurement of romantic love. Journal of Personality and Social Psychology, 16, 265-273. 
Rusbult, C. E. (1980). Commitment and satisfaction in romantic associations: A test of the investment model. Journal of Experimental Social Psychology, 16, 172-186.

Schroder, H. M., Driver, M. J., \& Streufert, S. (1967). Human information processing. New York: Holt, Rinehart, \& Winston.

Shaver, P. R., \& Brennan, K. A. (1992). Attachment styles and the "Big 5" personality traits: Their connections with each other and with romantic relationship outcomes. Personality and Social Psychology Bulletin, 18, 536-545.

Shaver, P. R., Collins, N., \& Clark, C. L. (1996). Attachment styles and internal working models of self and relationship partners. In G. J. O. Fletcher \& J. Fitness (Eds.), Knowledge structures in close relationships: A social psychological approach (pp. 25-61). Mahwah, NJ: Erlbaum.

Sillars, A. L., Pike, G. R., Jones, T. S., \& Murphy, M. A. (1984). Communication and understanding in marriage. Human Communication Research, 10, 317-350.

Simpson, J. A. (1987). The dissolution of romantic relationships: Factors involved in relationship stability and emotional distress. Journal of Personality and Social Psychology, $53,683-692$.

Simpson, J. A., Ickes, W., \& Blackstone, T. (1995). When the head protects the heart: Empathic accuracy in dating relationships. Journal of Personality and Social Psychology, 69, 629-641.

Simpson, J. A., \& Rholes, W. S. (1994). Stress and secure base relationships in adulthood. In K. Bartholomew \& D. Perlman (Eds.), Attachment processes in adulthood. (181-204). London: Kingsley.

Simpson, J. A., Rholes, W. S., \& Nelligan, J. S. (1992). Support seeking and support giving within couples in an anxiety-provoking situation: The role of attachment styles. Journal of Personality and Social Psychology, 62, 434-446.

Simpson, J. A., Rholes, W. S., \& Phillips, D. (1996). Conflict in close relationships: An attachment perspective. Journal of Personality and Social Psychology.

Smither, S. (1977). A reconsideration of the developmental study of empathy. Human Development, 20, 253-276. 
Stinson, L., \& Ickes, W. (1992). Empathic accuracy in the interactions of male friends versus male strangers. Journal of Personality and Social Psychology, 62, 787-797.

Surra, C. A., \& Longstreth, M. (1990). Similarity of outcomes, interdependence, and conflict in dating relationships. Journal of Personality and Social Psychology, 59, 501-516.

Tidwell, M. O., Reis, H. T., \& Shaver, P. R. (1996). Attachment, attractiveness, and social interaction: A diary study. Journal of Personality and Social Psychology, 71, 729745.

Wood, W., Christensen, N. P., Hebl, M. R., \& Rothgerber, H. (1997). Conformity to sex-typed norms, affect, and the self-concept. Journal of Personality and Social Psychology, 73, 523-535. 


\section{Footnotes}

1. Theory and past research indicate that greater attention to one's partner should beand is - associated with greater empathic accuracy. Colvin, Vogt, and Ickes (1997) compared five theoretical perspectives on accuracy in interpersonal judgment. They found that all five perspectives (see Funder, 1995; Karniol, 1990; Kenny, 1994; Smither, 1977; Stinson \& Ickes, 1992) assume that accuracy depends in part on perceivers' attention to and awareness of the actual behaviors displayed by target persons. In line with this assumption, Ickes et al. (1990) found that empathic accuracy in mixed-sex dyads is significantly correlated with the degree to which perceivers look at their partners (behavioral attentiveness) and the percentage of partnerrelevant thoughts and feelings they report (cognitive attentiveness). Similarly, Gesn (1997) has found that perceivers' ratings of their attention to and interest in an empathic accuracy task are significantly correlated with the quality of their performance on the task.

2. For evidence concerning the reliability and validity of the Collins and Read attachment scale, see Collins and Read (1990) and Griffin and Bartholomew (1994a, 1994b); for evidence about the reliability and validity of the IOS Scale, see Aron, Aron, \& Smolan (1990) and Aron et al. (1991).

3. Factor analyses revealed that, for men, one item from the Anxiety subscale did not load highly on either dimension. Thus, we dropped this item prior to constructing the two attachment dimensions for men.

4. The slides of the stimulus persons were taken from open, public records (either magazine ads or yearbooks from a college located more than 1000 miles away). Participants were told nothing about the stimulus persons except that they were involved in a "local dating pool." During debriefing, of course, participants were informed that the stimulus persons were not in a local dating pool. Although obtaining permission from the stimulus persons to use their pictures would have been preferable, it was impractical. It would have been difficult if not impossible to track down the names and current addresses of individuals who attended a college several years ago, particularly a college located so far away. 
5. Because lower empathic accuracy could result from distortions in the mean ratings of stimulus persons provided by certain people (such as more anxious people, who might be motivated to rate attractive stimulus persons as less physically and sexually appealing), we conducted another series of analyses on the physical/sexual attractiveness index. Specifically, we tested whether the attractiveness ratings made by people with different attachment dimension scores varied within either the higher threat or the milder threat experimental conditions. Treating men's and women's ratings on the physical and sexual attractiveness index as the dependent variable, we conducted two regression analyses (one for each sex) in which experimental condition (coded 2 if participants were assigned to the higher threat condition and 1 if they were assigned to the milder threat condition) was entered in Step 1, both attachment dimensions were entered as a block in Step 2, and the two threat by attachment interactions were entered in Step 3. No significant main effects or interactions were found for either sex. Any differential empathic accuracy exhibited by people with different attachment orientations, therefore, does not stem from systematic distortions in the ratings of the stimulus persons.

6. For articles providing statistical precedents, computational approaches, and conceptual rationales for this type of analysis, see Cohen and Cohen's (1983) discussion of the "adjusted analysis," Kenny and La Voie's (1985) discussion of the "adjusted individual-level correlation," and Gonzalez and Griffin's (1997) discussion of the "individual-level correlation."

7. A main effect for the threat condition also was found for men, Beta $=.26, t=2.35, p<$ .03. Specifically, men checked their partners' reactions more often in the higher threat condition $(\mathrm{M}=3.05$ checks during the slide rating task) than in the milder threat condition $(\mathrm{M}=2.16$ checks).

8. For each of the analyses reported above, we also partialed out participants' scores on the global relationship quality index. We performed these analyses to determine whether the attachment dimensions explained variance in the dependent measures above and beyond that accounted for by relationship quality per se. When relationship quality was statistically controlled, all of the significant effects for the attachment dimensions remained either significant or marginally significant. Thus, the effects reported above are not due to differences in the 
quality of the relationships of men and women with different standings on the two attachment dimensions. 


\section{Figure Captions}

Figure 1. Interaction between attachment anxiety and empathic accuracy predicting changes in subjective closeness for women and men (combined). Regression lines are plotted for individuals scoring one-half a SD above and below the mean on the anxiety attachment dimension. Scores on the $y$-axis reflect pre-to-post changes in subjective closeness. Positive scores indicate increased closeness, 0 indicates no change, and negative scores indicate decreased closeness.

Figure 2. Interaction between attachment anxiety and empathic accuracy predicting the probability of relationship stability (at the 4-month follow-up) for men. Regression lines are plotted for men scoring one-half a SD above and below the mean on the anxiety attachment dimension. Scores on the y-axis reflect the probability of relationship stability, which can range from 1.0 (still dating) to 0 (no longer dating). 